DoE/AL/99852-.T/

\title{
Annual Progress Report on the Development of a 2 MW/10 Second Battery Energy Storage System for Power Disturbance Protection
}

DOE Co-Op Agreement \#DE-FC04-94AL99852

RECEIVED FEB $0>1996$

OSTI

DDEFCO4-94AL99852

January 29, 1996

Omnion Power Engineering Corporation P.O. Box 879 2010 Energy Drive

East Troy, Wisconsin 53120 414-642-7200

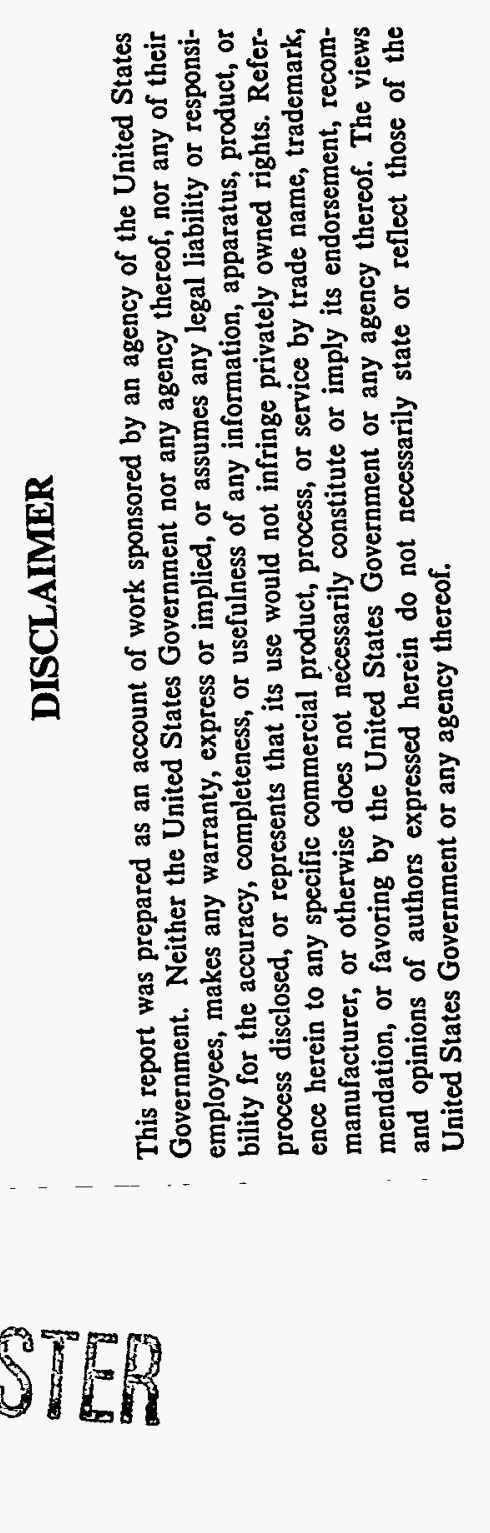




\section{TABLE OF CONTENTS}

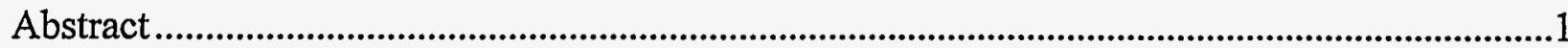

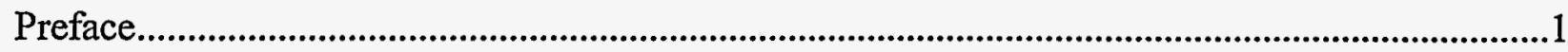

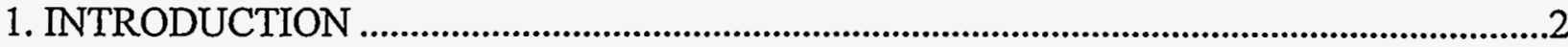

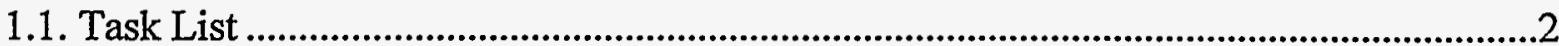

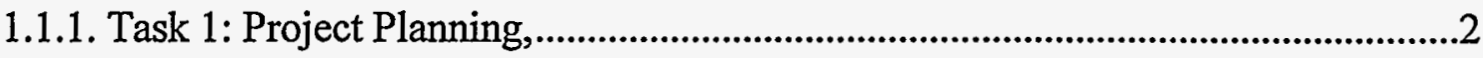

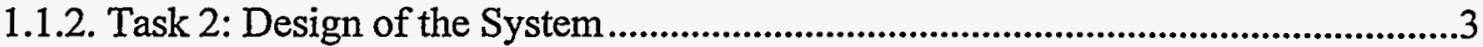

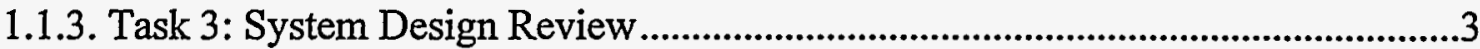

1.1.4. Task 4: Hardware Procurement ...........................................................................3

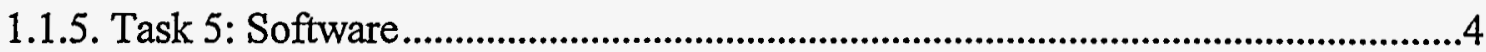

1.1.6. Task 6: Prototype Test................................................................................4

1.1.7. Task 7: Design Modifications ............................................................................4

1.1.8. Task 8: Manufacture Balance (7 Modules) of $2 \mathrm{MW} / 10$ Second System ............5

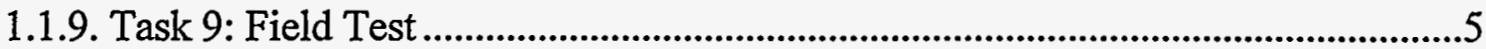

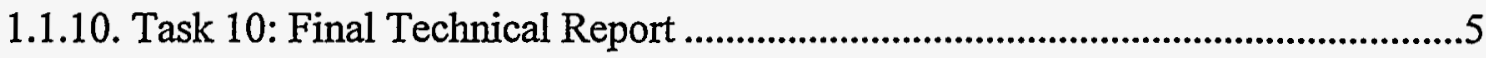

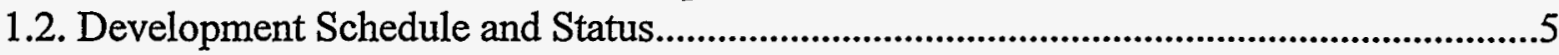

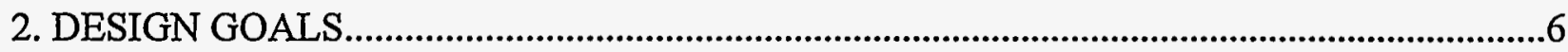

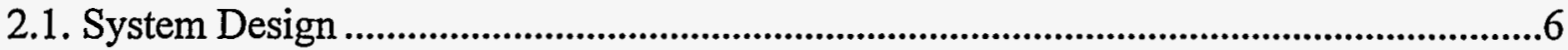

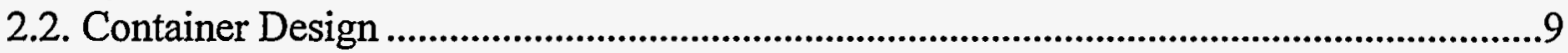

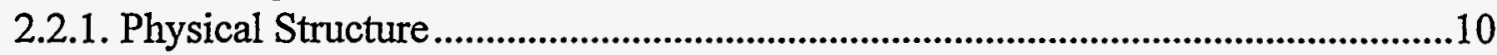

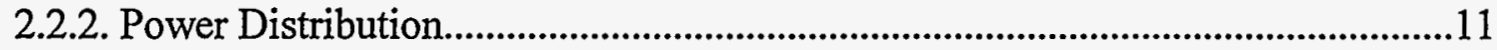

2.2.3. Module Interface..........................................................................................12

2.2.4. Auxiliary System Hardware and Power System...............................................13

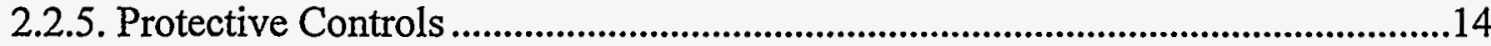

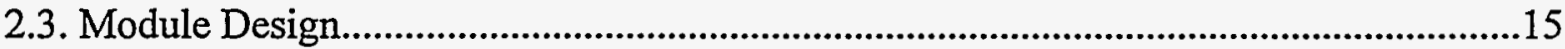

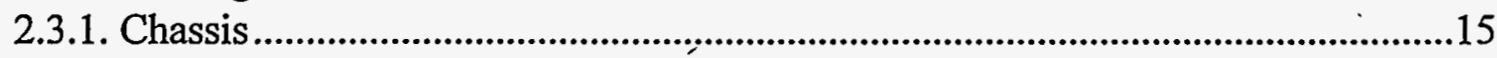

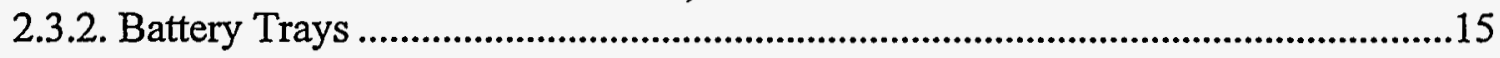

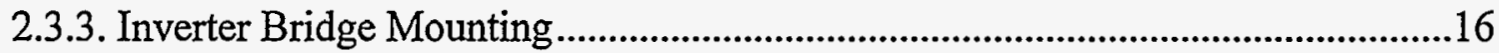

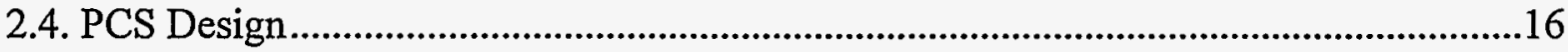

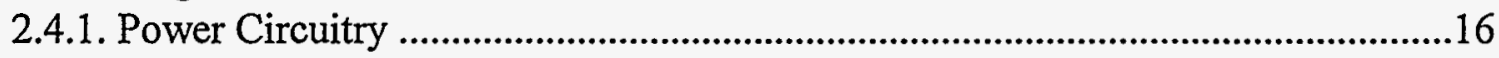

2.5. Static Automatic Transfer Switch (SATS) and Isolation Transformer...........................16

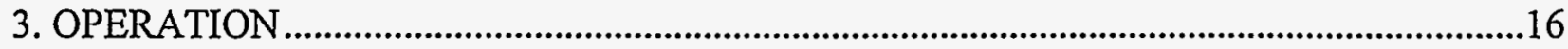

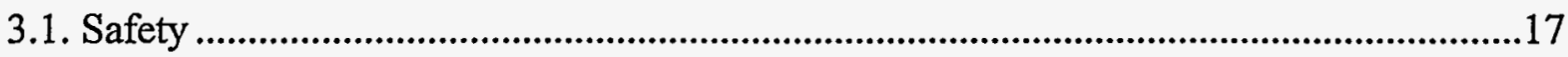

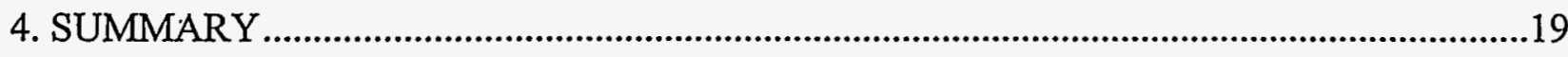

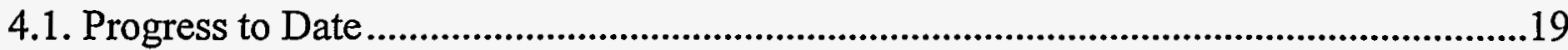

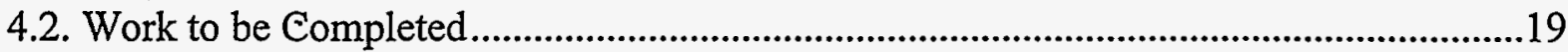




\section{List of Figures}

Figure 1. AC Battery PQ2000 System Container .......................................................................

Figure 2. Static Automatic Transfer Switch ..............................................................................

Figure 3. System Auto Transformer ........................................................................................

Figure 4. Typical AC Battery PQ2000 Site Layout Plan...................................................................

Figure 5. AC Battery System Container with Doors Open.............................................................10

Figure 6. Forklift Loading of Battery Modules ...........................................................................10

Figure 7. AC Battery System Container with "Cap Banks" ...........................................................11

Figure 8. System Container Power Wiring ...................................................................................11

Figure 9. Power Wiring Current Transmitter.............................................................................12

Figure 10. System Power Cable Cam-Loc Connectors and Fiber Optic Cables.............................12

Figure 11. Cam-Loc Cable Connector Panel on System Battery Module ......................................12

Figure 12. Fuse Panel Inside Center Electrical Compartment ........................................................13

Figure 13. PQ2000 Control System LCD Display ....................................................................14

Figure 14. PQ2000 System Battery Module ...............................................................................15

Figure 15. Top View of PQ2000 Battery Module .......................................................................15

Figure 16. PQ2000 PCS Panel Under Test ...............................................................................16

Figure 17. PQ2000 System Smoke and Hydrogen Detectors ......................................................18

Figure 18. Container Acid Spill Containment Area...................................................................18

\section{APPENDICES}

Appendix A System One Line Electrical Diagram

Appendix B System Container Structural Drawing 


\begin{abstract}
Sandia National Laboratories (SNL), acting for the U.S. Department of Energy (DOE), contracts for and administers programs for the purpose of promoting the development and commercialization of large scale, transportable battery energy storage systems. Under DOE CoOp Agreement No. DE-FC04-94AL99852, SNL has contracted for the development and delivery of an initial prototype $250 \mathrm{~kW}$ bridge that becomes an integral subsystem of a $2 \mathrm{MW} / 10$ Second System that can be used by utility customers to protect power sensitive equipment from power disturbances. Development work includes field installation and testing of the prototype unit at a participating utility site for extended product testing with subsequent relocation to an industrial or commercial participating utility customer site for additional evaluation. The program described by the referenced document calls for cost sharing with the successful bidder and eventual title transfer to the participating utility. Prototype delivery is scheduled for January of 1996, with a period of two years allowed for field testing. A final report summarizing the test data with conclusions and recommendations is part of the contract.
\end{abstract}

\title{
Preface
}

Voltage sags and power outages that last on the order of cycles to several seconds are common on utility systems. These sags and outages are a result of normal utility switching associated with re-closer schemes, large starting currents required by certain types of equipment, or system faults and pose serious problems for many commercial power consumers with voltage sensitive loads such as process controls, hospital medical equipment, and other critical loads. These momentary disturbances can cause equipment shutdowns which may result in downtime, cleanup, and complete restart sequencing of manufacturing lines. A single disturbance may result in related costs of up to $\$ 1$ million.

This report outlines the development work of a 2 MVA battery energy storage system including the power conversion equipment (PCS) and a solid state power transfer switch to provide uninterrupted power to an industrial customer. The system will monitor the utility grid for disturbances, disconnect the critical load from the utility, and seamlessly reconnect reliable power to the load from the PQ2000 system control for the duration of the utility disturbance up to 10 seconds at a power level of up to $2 \mathrm{MVA}$. Upon verification that the utility is again stable, it then seamlessly returns the load to the utility. A one-line electrical diagram of the system is provided in Appendix A of this report.

This report summarizes project development work conducted between September 1, 1994, through August 31, 1995. Included in the development is system design, hardware component procurement for a $250 \mathrm{kVA}$ battery module building block, battery module and system software development and battery module prototype testing. Actual work conducted and reported on is outlined in the Task List and Development Schedule provided in the Section 1.0 of this report. 


\section{INTRODUCTION}

The concept of applying battery energy storage to resolve large scale industrial and commercial power management and power quality problems is not new. Government funded support for the development of a large scale, modular battery energy storage system was initiated in 1991, when the U. S. Department of Energy through Sandia National Laboratories issued a contract to Omnion Power Engineering Corporation to design and deliver an " $\mathrm{AC}$ battery" aimed at promoting battery energy storage for commercial applications. Work initiated by Omnion Power Engineering to refine and enhance system designs for this project led to the formation of strategic partnerships with key suppliers under the umbrella of a new corporate identity known as AC Battery Corporation.

AC Battery Corporation was organized expressly for the development and manufacture of largescale, modular, turnkey battery energy storage systems as a successful bidder on a cost-shared, government funded project. Initial work conducted by $\mathrm{AC}$ Battery led to successful bidding on several follow-on projects requiring large capital development investment. The demand for capital investment led to the eventual purchase of AC Battery by General Motors in October of 1994.

Work performed under this contract was aimed at delivering a battery energy storage system designed to protect utility customers from the detrimental effects of power quality disturbances on power sensitive electronic equipment. AC Battery Corporation initiated development of a modular, transportable concept with Omnion Power Engineering Corporation supplying key power conversion technology and acting as a primary component and subsystem supplier.

\subsection{Task List}

The scope of work defined by the Project award was organized into several tasks with timelines for delivery established. The following task list was developed in conjunction with a Gantt Chart and used as a project management tool. The task list outlined below and schedule of deliverables was used to evaluate vendor delivery performance.

\subsubsection{Task 1: Project Planning,}

Input: $\quad$ System abstract and completion of $250 \mathrm{kVA}$ bridge development

Objective: Fully define the deliverables in terms of hardware, performance, schedule, and documentation

Develop system specification

Develop project schedule

Develop estimated costs

Output: $\quad$ System specification document

Project schedule 
Cost breakdown

System one-line diagram

\subsubsection{Task 2: Design of the System}

Input: $\quad$ System specifications and one-line diagram

Objective: To develop component specifications to design control algorithms for:
a. $\quad 250 \mathrm{~kW}$ module
b. $2 \mathrm{MW}$ container
c. Static disconnect switch

To develop electrical schematics/bill of materials (BOM) and component layout drawings for:
a. $\quad 250 \mathrm{~kW}$ module printed circuit (PC) boards
b. $\quad 250 \mathrm{~kW}$ converter/charger power package
c. $2 \mathrm{MW}$ container control $\mathrm{PC}$ board
d. Complete system

To develop mechanical drawings/BOM:
a. $\quad 250 \mathrm{~kW}$ module
b. $2 \mathrm{MW}$ container
c. 2 MVA static disconnect switch

To outline support documentation:
a. Factory test plans
b. Field test plan
c. Operations and Maintenance Manual

Output: $\quad$ System schematic/BOM

Sub-assembly and PC board schematics/BOM

Artwork for PC boards

Control diagrams/flow charts or pseudo-code

Cabinet detail drawings

BOM for test equipment.

Outline for test plans and operations \& maintenance manual

\subsubsection{Task 3: System Design Review}

Input: $\quad$ System design

Objective: To provide final technical review of concepts being implement

Output: Design approval

\subsubsection{Task 4: Hardware Procurement \\ Input: Bills of Material \\ PC board artwork \\ Cabinet detail drawings \\ Component specifications}


Objective: To identify competitive sources and purchase prototype $250 \mathrm{~kW}$ module components as specified by engineering To manage the procurement so as to meet schedule demands

Output: $\quad$ All system component hardware

\subsubsection{Task 5: Software}

Input: $\quad$ System specification

$250 \mathrm{~kW}$ module hardware design

$2 \mathrm{MW}$ container hardware design

Container control algorithm

Static switch control algorithm

Objective: To write the code to implement the control algorithms for the modules and container

The code will be detailed enough to enable testing of the hardware as the PC boards and modules are prototype

Output: $\quad$ Compiled code for each processor/computer in the system

\subsubsection{Task 6: Prototype Test}

Input: $\quad$ Components for a $250 \mathrm{~kW}$ module

Preliminary software

Assembly documentation

Test procedures

Objective: To build and test individual PC boards

To build and test a $250 \mathrm{~kW}$ converter

To build and test a $5 \mathrm{~kW}$ charger

To build and test an assembled $250 \mathrm{~kW}$ module as a stand-alone unit

To prototype and test a $250 \mathrm{~kW}, 10$ second module including the static disconnect switch

Output: $\quad$ Hardware and software prototypes that prove the stand-alone and alternating current $(\mathrm{AC})$ bus support concepts

Preliminary test data and summary of system performance Completed PC board test procedures

\subsubsection{Task 7: Design Modifications}

Input: $\quad$ Test results and marked-up drawings from prototype testing

Objective: To implement design and documentation changes as necessary to allow procurement of components and production of seven additional $250 \mathrm{~kW}$ modules

Output: $\quad$ Updated schematics, BOMS, and mechanical drawings Procurement listing of components for seven new $250 \mathrm{~kW}$ modules Updated software 
Field test procedures

\subsubsection{Task 8: $\quad$ Manufacture Balance ( 7 Modules) of 2 MW/10 Second System}

Input: Updated schematic, BOM, mechanical drawings

Objective: Manufacture and test seven identical modules

Package all modules in a system container ( $2 \mathrm{MW} / 10 \mathrm{Sec})$

Output: $\quad$ Completed, factory tested $2 \mathrm{MW} / 10$ second battery energy storage system - PQ2000

\subsubsection{Task 9: Field Test}

Input: $\quad$ Field test procedures

Objective: Actual site test over an extended period of time

Collect performance data and analyze

Output: $\quad$ Field test report

\subsubsection{Task 10: Final Technical Report}

Input: $\quad$ All documentation in Task 1 through Task 9

Objective: Draft concise report of project and results

Report will include drawings, procedures, test reports, and conclusion

Output: $\quad$ Final technical report

\subsection{Development Schedule and Status}

\begin{tabular}{|lcccc|}
\hline \multicolumn{1}{|c}{ Task } & Total Hrs & $\begin{array}{c}\text { Scheduled } \\
\text { Start }\end{array}$ & $\begin{array}{c}\text { Scheduled } \\
\text { Finish }\end{array}$ & Status \\
\hline PQ2000 Project & $\mathbf{5 2 4 0}$ & $\mathbf{1 0 - 0 3 - 9 4}$ & $\mathbf{1 1 - 2 0 - 9 5}$ & \\
Task 1 Project Plan & 360 & $10-03-94$ & $11-02-94$ & Complete \\
Task 2 Design & 1560 & $11-02-94$ & $04-19-95$ & Complete \\
System Modeling & 240 & $11-18-94$ & $01-20-95$ & Complete \\
System Schematic/BOM & 440 & $11-02-94$ & $12-13-94$ & Complete \\
PCB Schematic/BOM & 180 & $12-26-94$ & $03-17-95$ & Complete \\
PCB Artwork & 80 & $04-04-95$ & $04-19-95$ & Complete \\
Control Diagrams & 140 & $12-13-94$ & $02-10-95$ & Complete \\
Cabinets & 280 & $11-02-94$ & $12-19-94$ & Complete \\
Outlines test, O\&M & 80 & $12-13-94$ & $02-15-95$ & $40 \%$ \\
Charger Assembly & 120 & $11-28-94$ & $01-25-95$ & $70 \%$ \\
Task 3 Design Review & 180 & $02-15-95$ & $03-22-95$ & Complete \\
Task 4 Hardware Purchase & 100 & $12-13-94$ & $02-22-95$ & $98 \%$ \\
Task 5 Software & 300 & $12-28-94$ & $03-27-95$ & \\
Static Switch & 20 & $03-22-95$ & $03-27-95$ & $85 \%$ \\
Charger & 120 & $12-28-94$ & $01-20-95$ & $90 \%$ \\
Controls & 160 & $02-10-95$ & $03-15-95$ & $90 \%$ \\
\hline
\end{tabular}




\begin{tabular}{|lcccc|}
\hline Task 6 Preliminary & 880 & $03-27-95$ & $06-02-95$ & \\
Preliminary Product & 680 & $03-27-95$ & $05-18-95$ & Complete \\
Preliminary Test & 200 & $05-18-95$ & $06-02-95$ & $88 \%$ \\
Task 7 Design Modifications & 60 & $06-02-95$ & $06-07-95$ & $90 \%$ \\
Task 8 Final & 940 & $06-07-95$ & $07-28-95$ & \\
Final Production & 300 & $06-07-95$ & $06-16-95$ & $80 \%$ \\
Factory Test & 640 & $06-07-95$ & $07-28-95$ & $60 \%$ \\
Task 9 Field Test & 420 & $08-15-95$ & $10-18-95$ & \\
Task 10 Final Report & 440 & $10-18-95$ & $11-20-95$ & \\
\hline
\end{tabular}

Table 1. Development Schedule and Completion Status

\section{DESIGN GOALS}

The AC Battery PQ2000 Power Quality System has been designed to be an immediate-response, high-capacity, quick-discharge energy storage system that is capable of providing up to 2 MVA of clean power for up to 10 seconds and can switch sensitive industrial loads from utility service to full alternative, clean-power operation in approximately $1 / 4$ cycle. The AC Battery PQ2000 Power Quality System is designed to operate as a voltage source supplying and maintaining all power levels up to a maximum rating of 2 MVA for 10 seconds.

One of the major goals of this project was to design and build the PQ2000 to meet the required performance specifications while utilizing only existing, state-of-the-art technology and current high-volume production components of proven reliability. The objective was to combine these technologies in unique fashion to produce a modular, fully self-supporting, self-sustaining, transportable battery energy storage package that could be completely factory assembled and tested before being transported to the customers site.

At this stage of the development process, it can be asserted that those objectives have been achieved. All components used in the fabrication of the AC Battery PQ2000 Power Quality System are commercially available from vendors serving other markets. These components are factory assembled and tested under rigorous quality control standards to create a fully operational, highly reliable, modular, battery energy storage system. No part of the system design or technology used is considered experiméntal, but the project is developmental.

\subsection{System Design}

The proposed AC Battery PQ2000 Power Quality System is comprised of three main components-the PQ2000 container, a 2 MVA Electronic Selector Device (ESD) with additional switchgear, and a 2 MVA/15 Second, 208/480 V isolation transformer. See Figure 1 through 3.

The PQ2000 System is modular by design. Unlike traditional battery storage systems that bus together numerous battery strings through specialized high-voltage DC switchgear and custom-built converters, the PQ2000 aggregates AC power from multiple 
battery modules which are paralleled to achieve the desired system capacity. This modular, building-block approach gives the PQ2000 great flexibility in meeting system sizing and layout requirements.

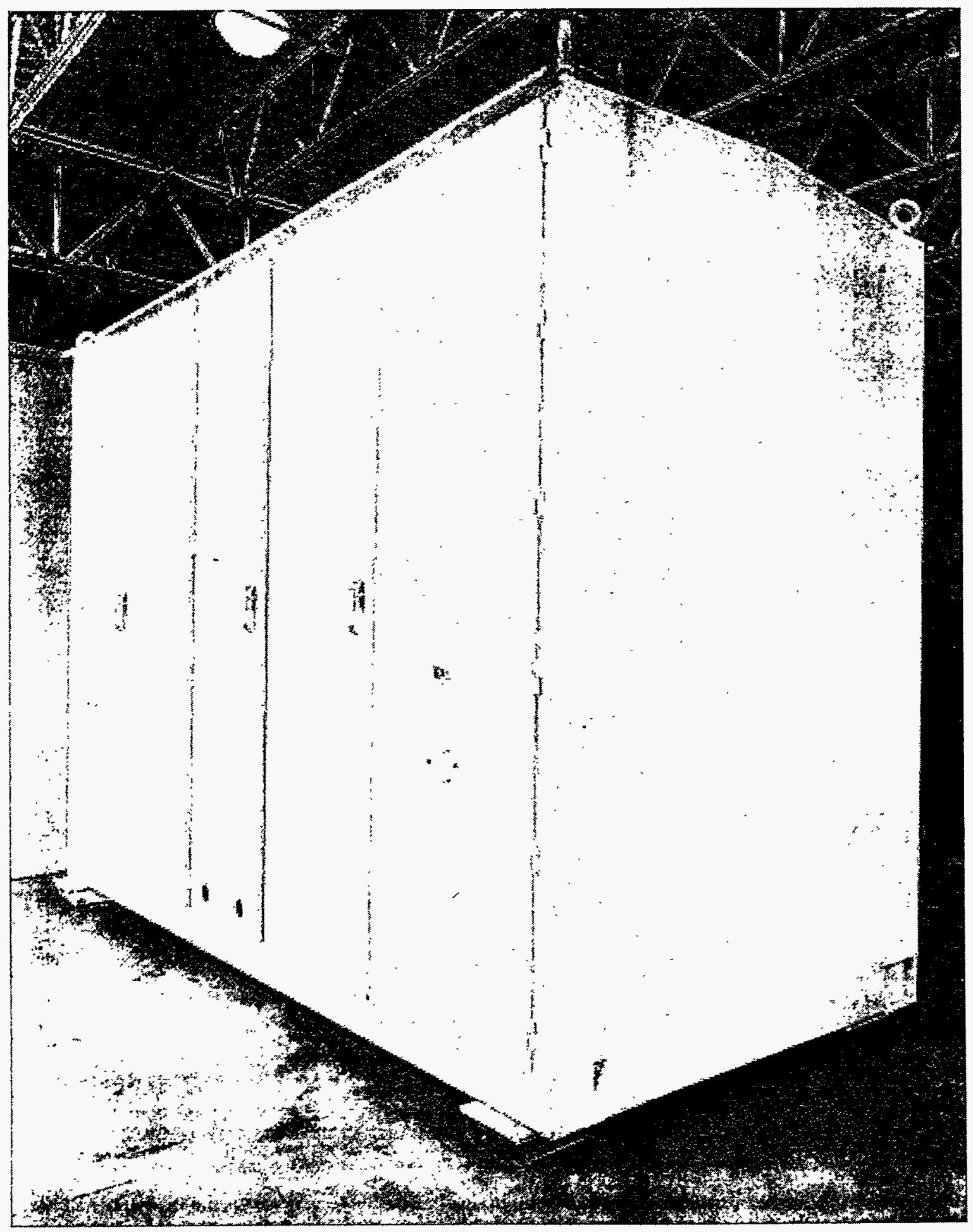

Figure 1. AC Battery PQ2000 System Container 


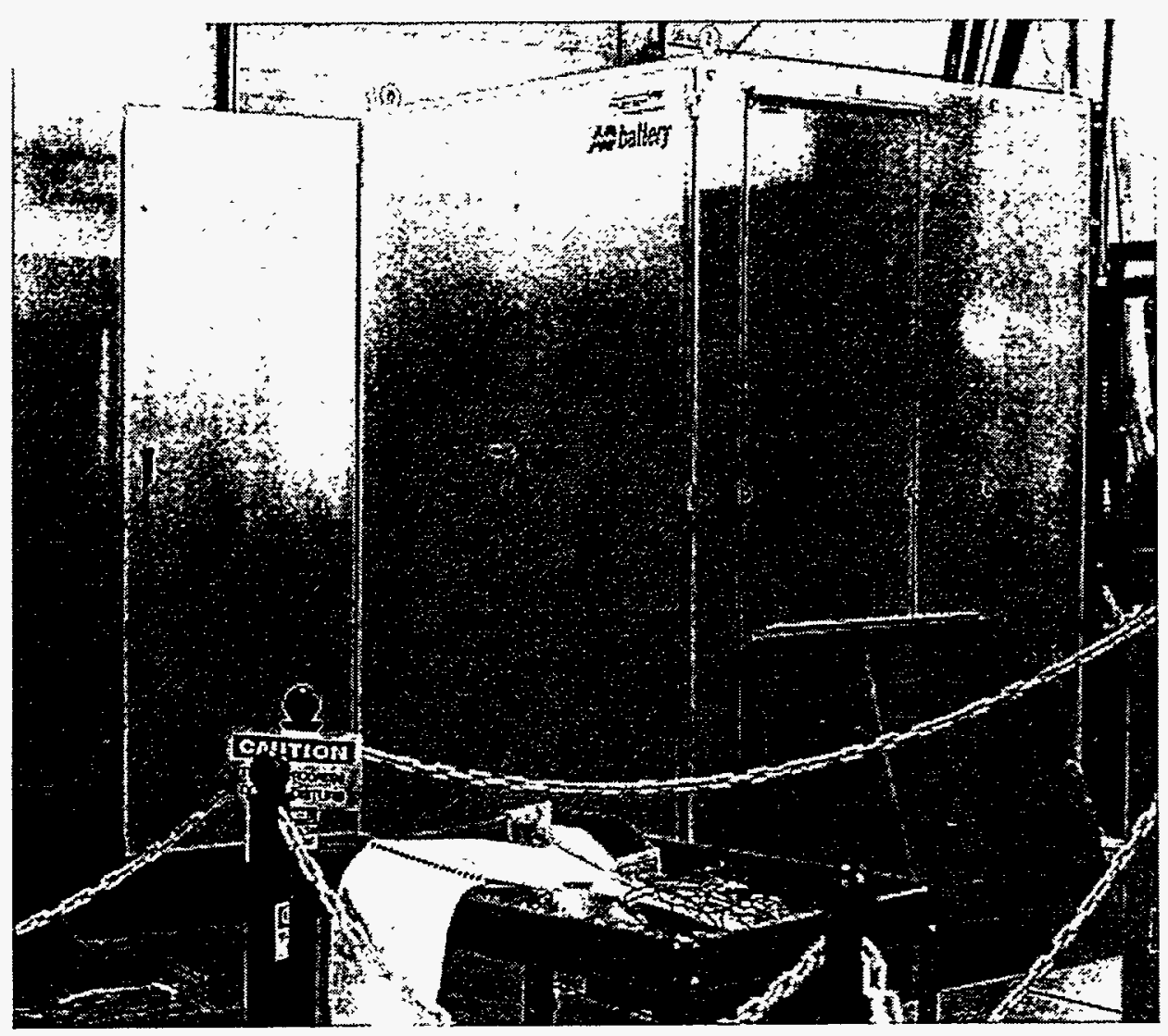

Figure 2. Static Automatic Transfer Switch

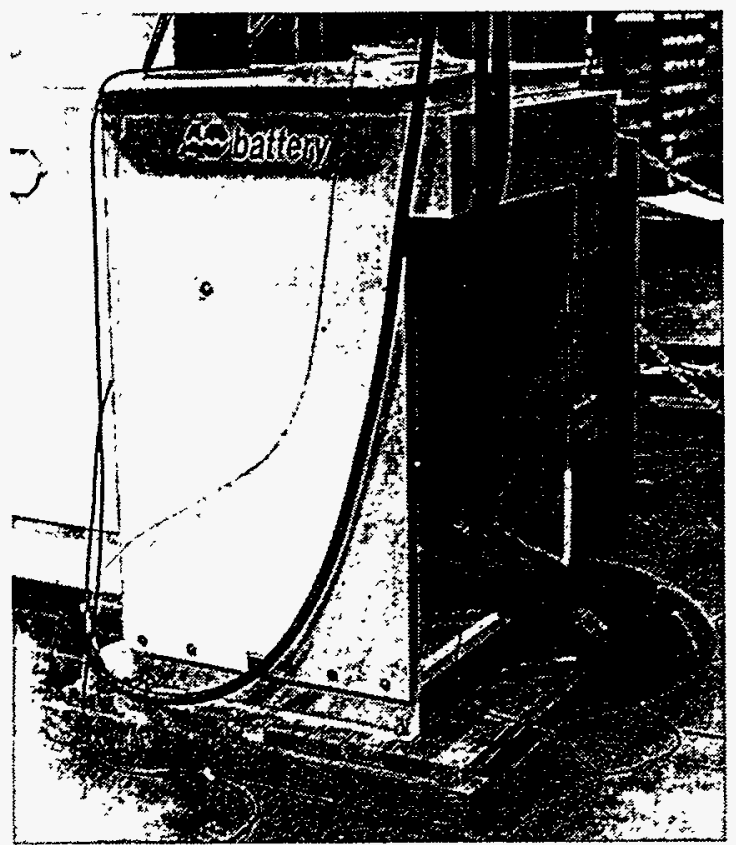

The recommended installation site plan of the PQ2000 calls for an area of 1178 square feet. Eleven feet of access around the container is suggested for fork lift maneuvering to load and unload the battery modules. Clearance around the SATS and isolation transformer may be reduced, codes and other local restrictions permitting. See Figure 4 for a typical site layout plan.

Once activated, the PQ2000 Power Quality System is designed to operate automatically and not require attended operation.

Figure 3. System Auto Transformer 


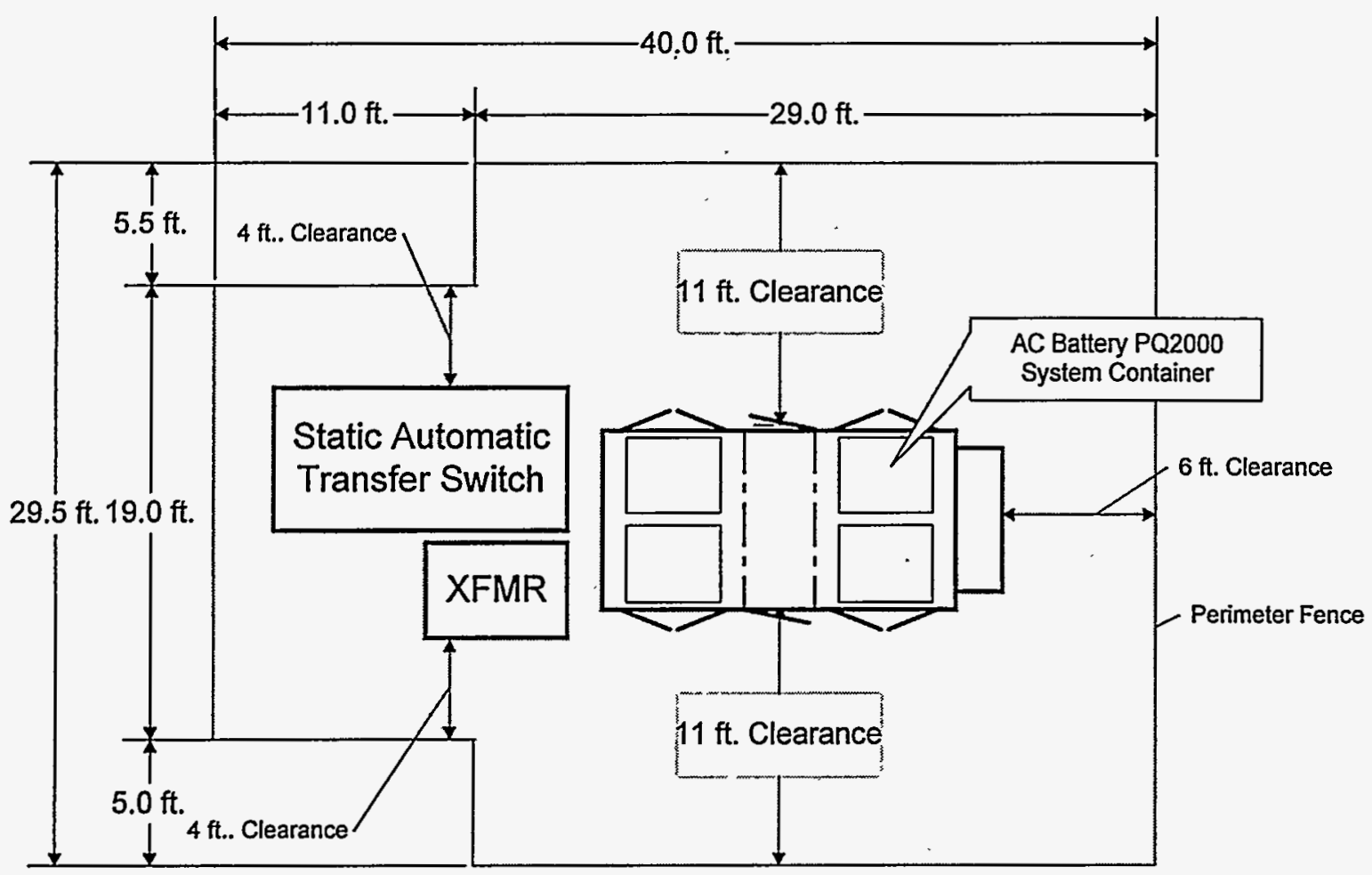

Figure 4. Typical AC Battery PQ2000 Site Layout Plan

\subsection{Container Design}

The system container had been designed to meet the requirements of a 20 -year life cycle. The container features heavy gauge steel construction with tubular steel internal structural supports, and a corrosion resistant exterior enamel finish. Urethane foam is sprayed over all interior surfaces with the exception of the floor for insulation purposes. An internal enamel finish is applied to protect the internal container surfaces against any potential corrosive conditions.

A finite element analysis was conducted on the container design to ensure that the system will withstand the repeated lifting and moving stresses related to transporting the containers as well as seismic events up to zone 4.

The container design includes provisions for mounting up to eight (8) AC Battery Modules, hydrogen venting system, system monitoring, HVAC equipment, and microprocessor based System Control. The PQ2000 system container is designed to be mounted outdoors in ambient conditions from $-20^{\circ} \mathrm{F}$ to $120^{\circ} \mathrm{F}$ and 0 to $100 \%$ humidity. The container is insulated to R-4.0. A structural drawing of the system container is provided in Appendix $B$ of this report. 


\subsubsection{Physical Structure}

The AC Battery System Container measures $15^{\prime}$ long, 7.5' wide, and 11' high and weighs approximately 42,000 pounds when prepared for shipment. The container is shipped on a lowboy, flatbed trailer. Preparation of the container for shipment

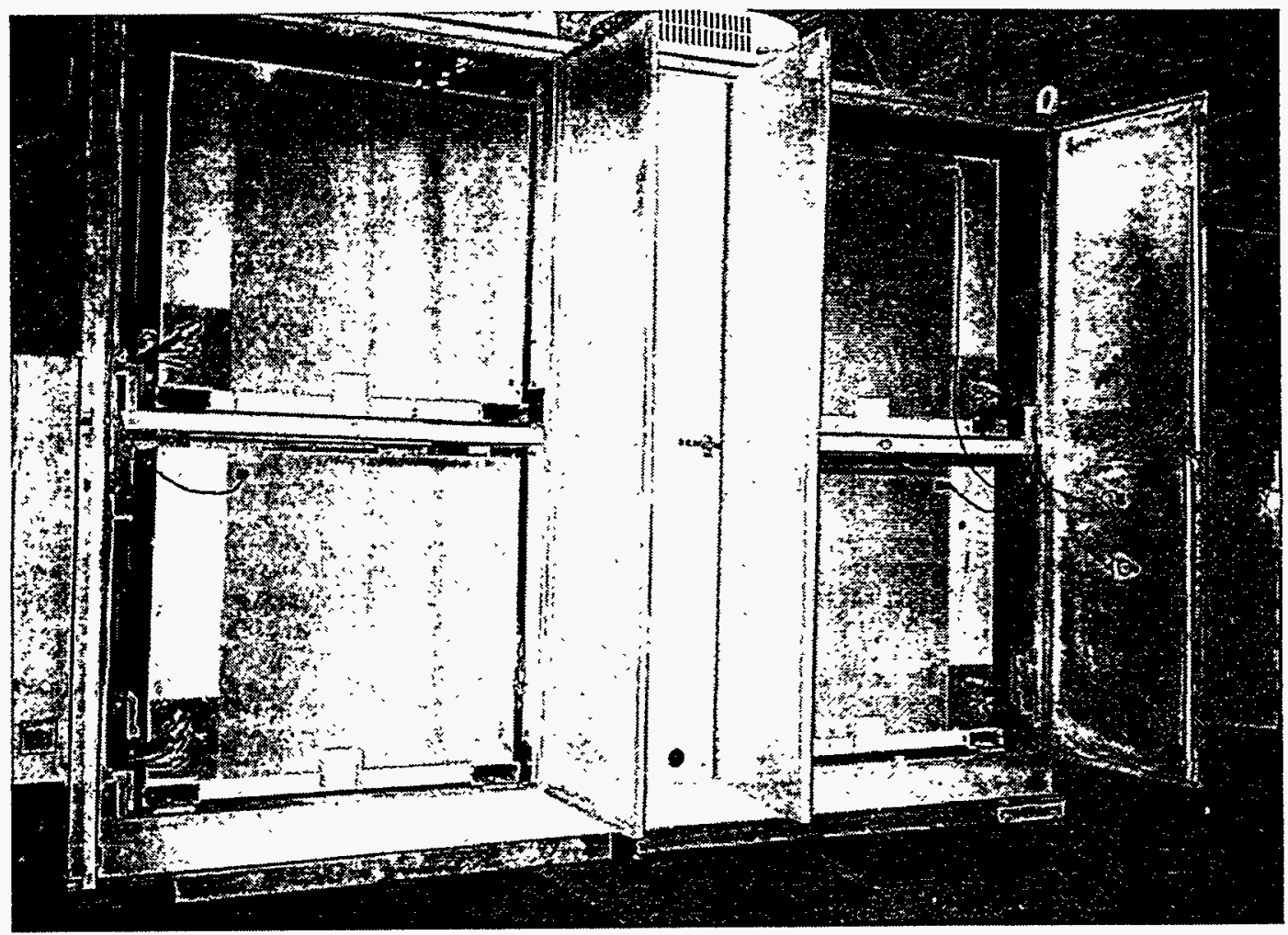

Figure 5. AC Battery System Container with Doors Open

includes removal and stowage of the rooftop mounted HVAC units. The battery modules remain inside the container during shipment.

The system container has two (2) sets of double doors for removing and replacing modules and two (2) electrical compartment access doors. Security provisions include key locks on the container access doors and panels. Figure 5 shows the container with the doors open. Figure 6 shows a forklift truck loading a module into the container.

The container door frames are sealed with weather stripping for protection against contamination from the elements. The container has been designed to withstand

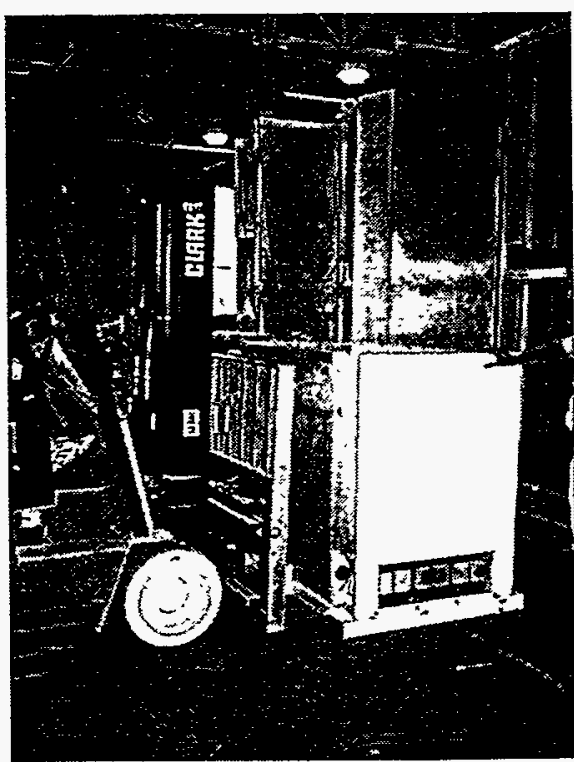

Figure 6. Forklift Loading of Battery Modules 
shock and vibration to $5 \mathrm{~g}$ 's and is rated for use in seismic 4 zones.

Passive input filters protect the Static Automatic Transfer Switch (SATS) against electrical input surges. Three rows of "capacitor banks" are mounted on the outside of the container. The "cap bands" are pictured in Figure 7.

\subsubsection{Power Distribution}

The AC Battery PQ2000 Power Quality System is modular in its power distribution wiring design. Each individual battery module has its own separate inverter bridge, battery charger and onboard microprocessor for data acquisition. The AC output of each module is wired in parallel with the other battery modules where total system output is aggregated.

Aggregating power output on the $\mathrm{AC}$ side of the power converter made it possible to eliminate high voltage $\mathrm{DC}$

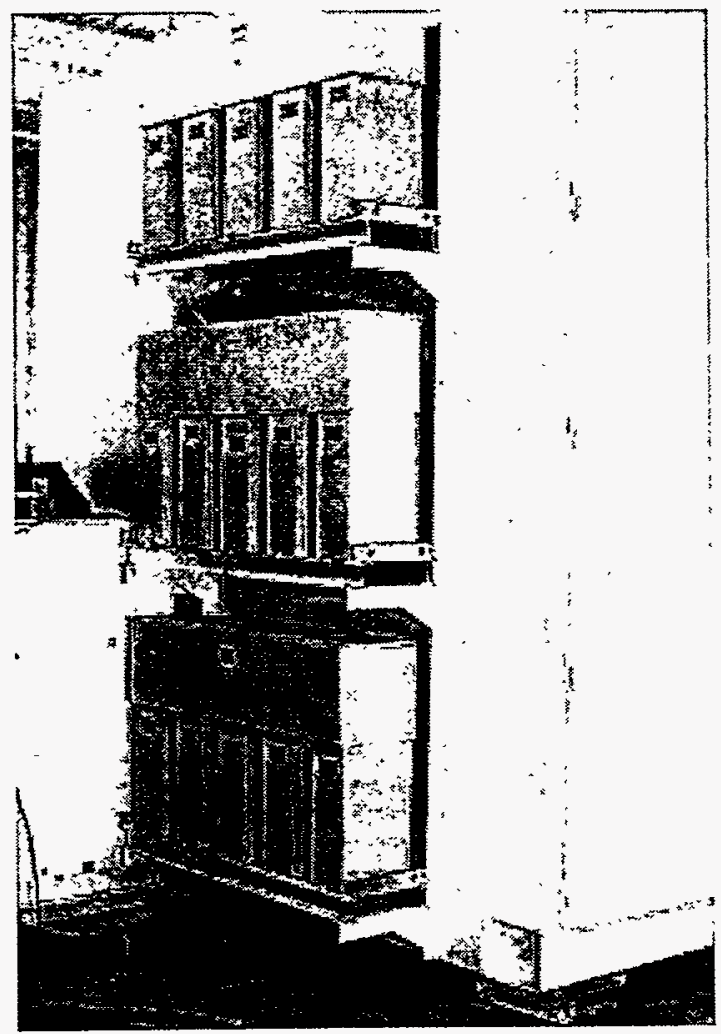

Figure 7. AC Battery System Container with "Cap Banks" switchgear and build system capacity by adding battery modules as required.

Special high voltage cables are run strung in an overhead bundles to the individual modules. See Figure 8. Cam-loc style connectors are used for easy connect/disconnect. Each of the three phases of power output from all modules is individually fused. A bank of fuses is mounted in the center electrical control cabinet.

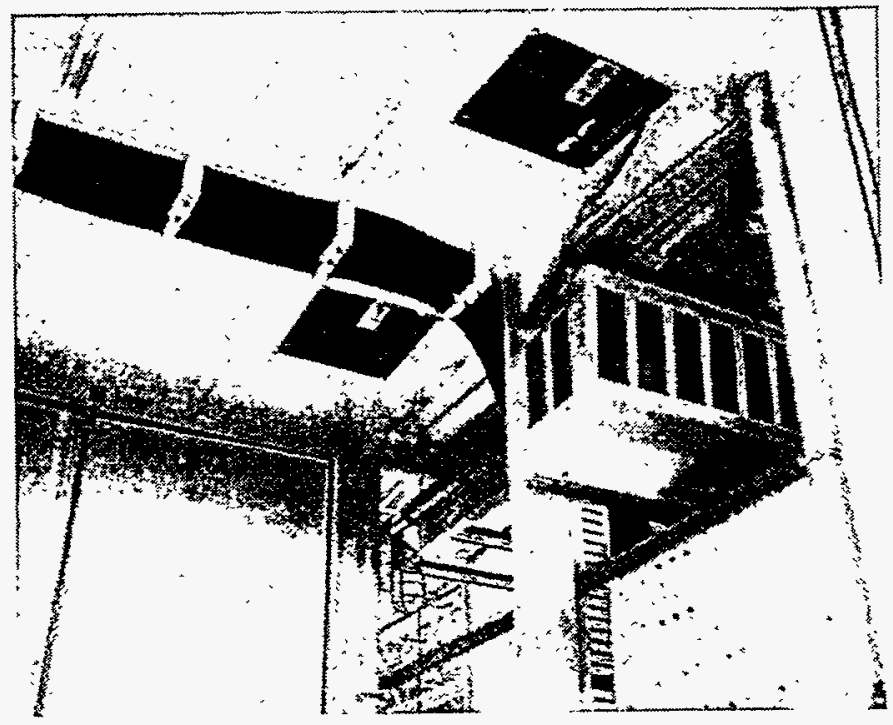

Figure 8. System Container Power Wiring 
Figure 9 shows one of the current transformers used to sense the current output of each phase of the aggregated output of the system. Insulated power cables with camloc connectors are used at the AC Battery Module connections while insulated boltlugged connectors are used for terminations at the power bus, isolation transformer, and SATS. Connections to the

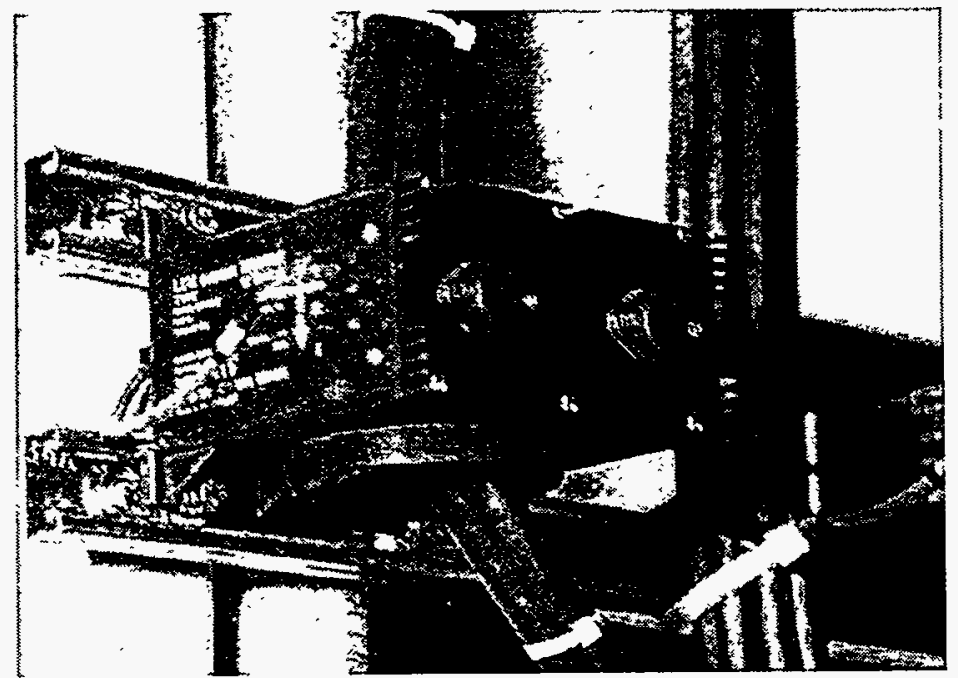

Figure 9. Power Wiring Current Transmitter

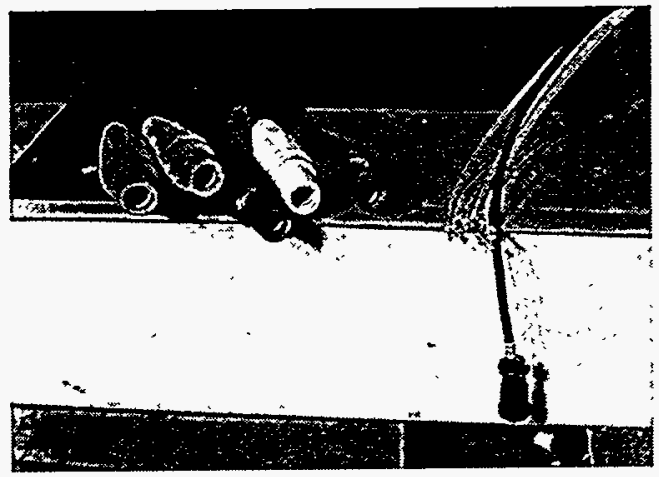

Figure 10. System Power Cable CamLoc Connectors and Fiber Optic Cables

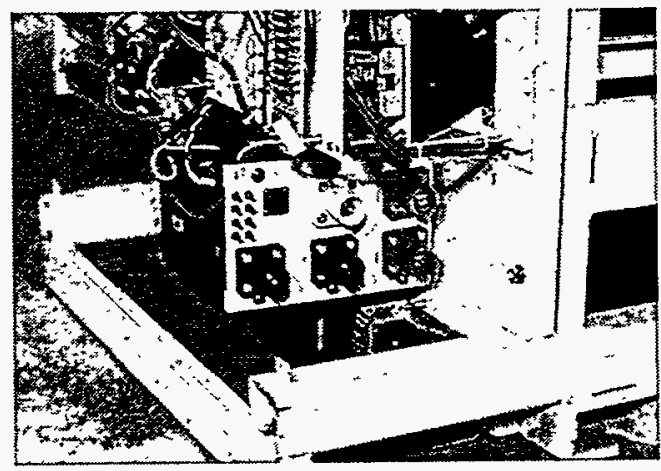

Figure 11. Cam-Loc Cable Connector Panel on System Battery Module

customer's $480 \mathrm{VAC}$ switchgear are also made using insulated electrical cables with bolted-lugged connections. Connecting power cables will be run in conduit from the container to the SATS, isolation transformer, and the customer's switchgear. Figure 10 shows the cam-loc connectors and Figure 11 shows the mating connector panel on the battery module.

\subsubsection{Module Interface}

Fiber optic cables are used for signal communications from the master system control and the module controllers. The computerized master control sends scaling commands via fiber optics to each battery module inverter bridge. 
The AC Battery PQ2000 Master Controller provides control and data acquisition for the system container and battery modules. It controls the eight (8) battery modules to operate and function together as a unified voltage source.

\subsubsection{Auxiliary System Hardware and Power System}

In the design of the AC Battery PQ2000 System, an Auxiliary Power System is used to power all auxiliary support systems and the master control computer. Power for the Auxiliary Power System is derived from the $208 \mathrm{VAC}$ power bus within the system container. The components of the Auxiliary Power System are located inside of the center section of the AC Battery System Container. The Auxiliary Power System connects the 208 $\mathrm{VAC}$ power bus to an $\mathrm{AC}$ fused disconnect. The AC fused disconnect then, in turn, supplies a single-phase $10 \mathrm{kVA}, 208: 240 / 120$ $\mathrm{V}$ Auxiliary Power Transformer. The 120 VAC single-phase output from the secondary of the Auxiliary Power Transformer then feeds the Auxiliary Power System distribution panel through a 50-amp main circuit breaker provided with the panel. Figure 12 to the right shows the fuse panel inside the center control cabinet. The respective auxiliary loads are fed

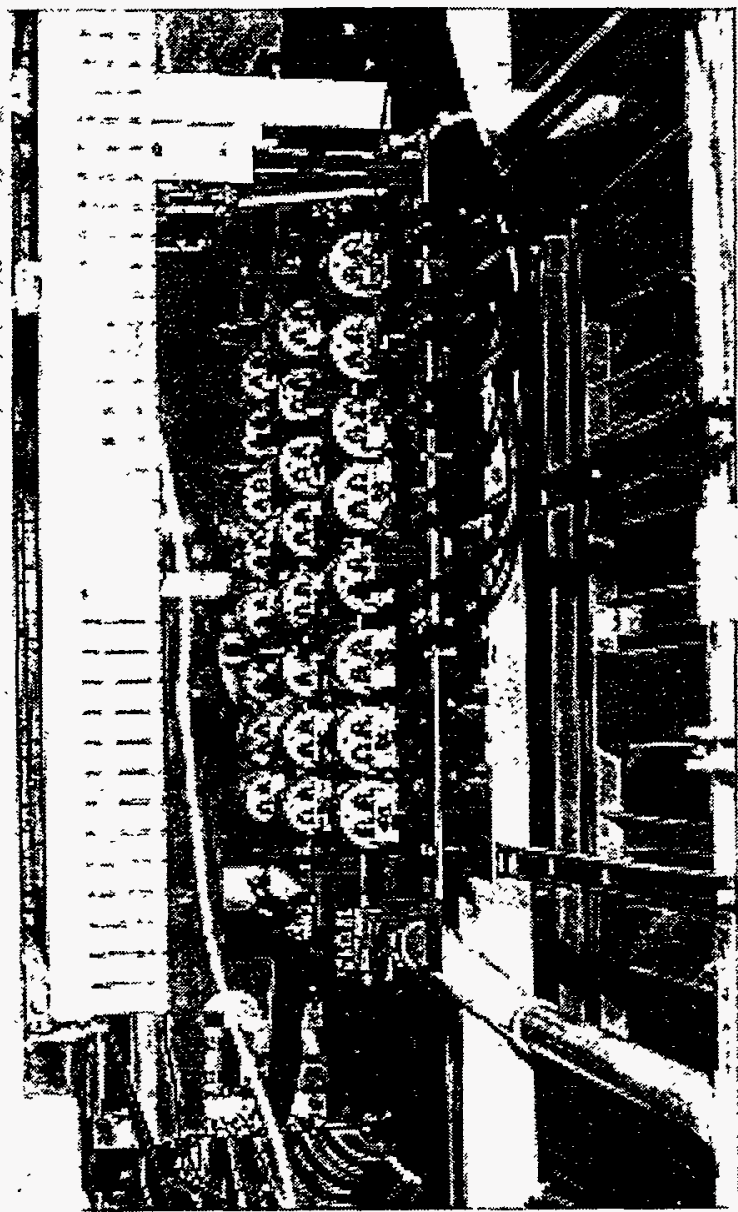

Figure 12. Fuse Panel Inside Center Electrical Compartment through separate circuits from the Auxiliary Power System distribution panel.

Auxiliary Power System loads include:

Qty Description

$4 \quad$ Air Conditioners

1 Heater

$1 \mathrm{H}_{2}$ Sensor

$1 \mathrm{H}_{2}$ Blower
Load (Watts)

2200/ea. 6000

6

40 
1 Air Curtain

2 Lights on Switches

4 Auxiliary Power Outlets

1 Auxiliary Power to the

AC Battery System Modules (8)

1 Control Power plus Other Miscellaneous Loads

1 System Control Computer
125

100/ea.

600/ea.

200

3000

200

\subsubsection{Protective Controls}

The AC Battery PQ2000 System PCS includes self-protective and self-diagnostic features to protect itself from damage in the event of a component failure or the excursion of operating parameters, which may be to internal or external causes beyond a safe or expected range. Error messages are displayed on an LCD display inside the center electrical control cabinet. Figure 13 below shows the LCD panel used by authorized service personnel to assist with maintenance troubleshooting.

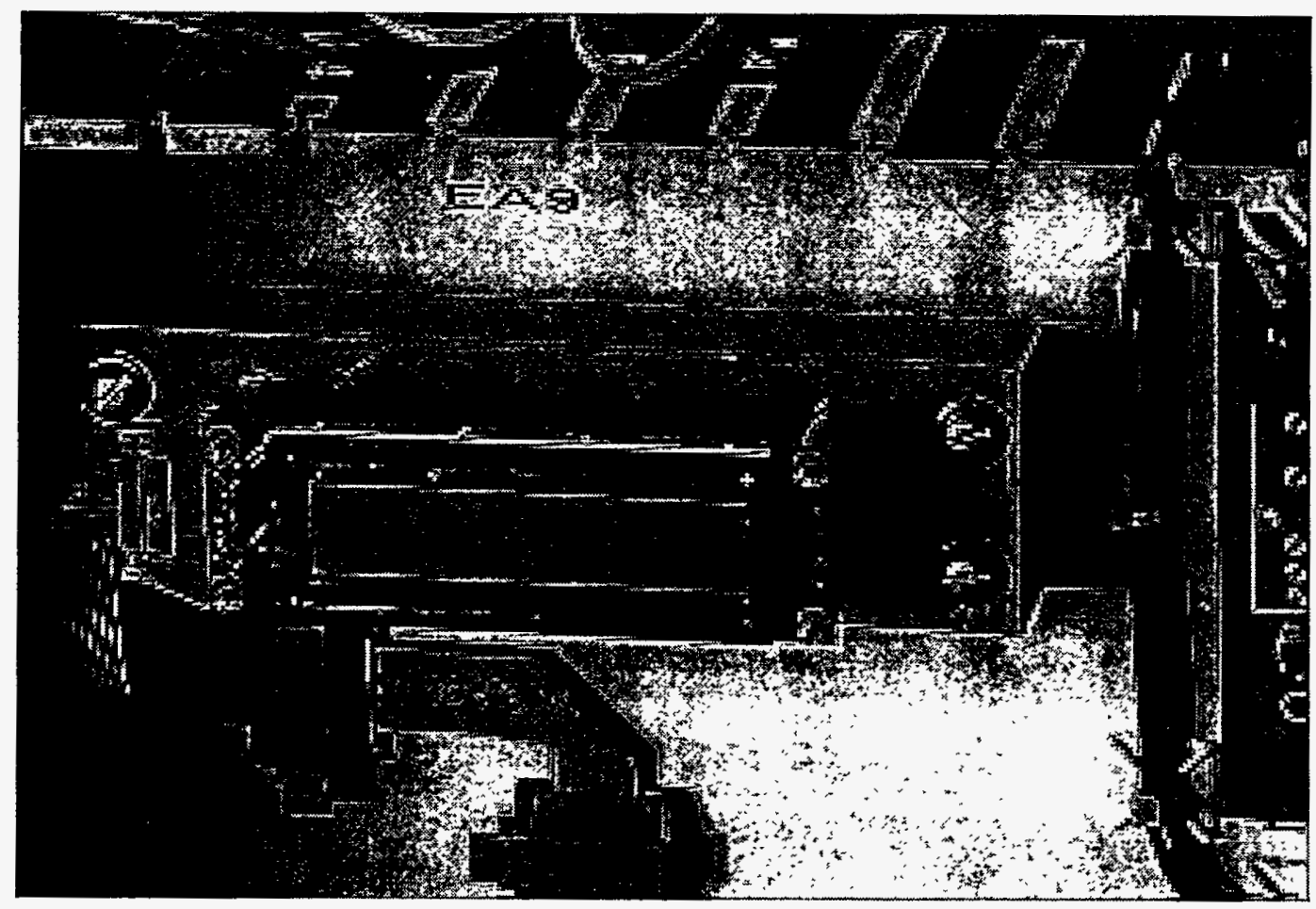

Figure 13. PQ2000 Control System LCD Display 


\subsection{Module Design}

The eight (8) battery modules contained in the AC Battery PQ2000 system container each house fortyeight (48) individual 12 volt batteries arranged in four (4) "rack "n stack" trays. The four (4) trays are secured to a base which is configured for lifting with a fork lift truck. Figure 14 to the right shows a photograph of the modular "rack "n stack" assembly (less the bridge assembly) mounted in the system container.

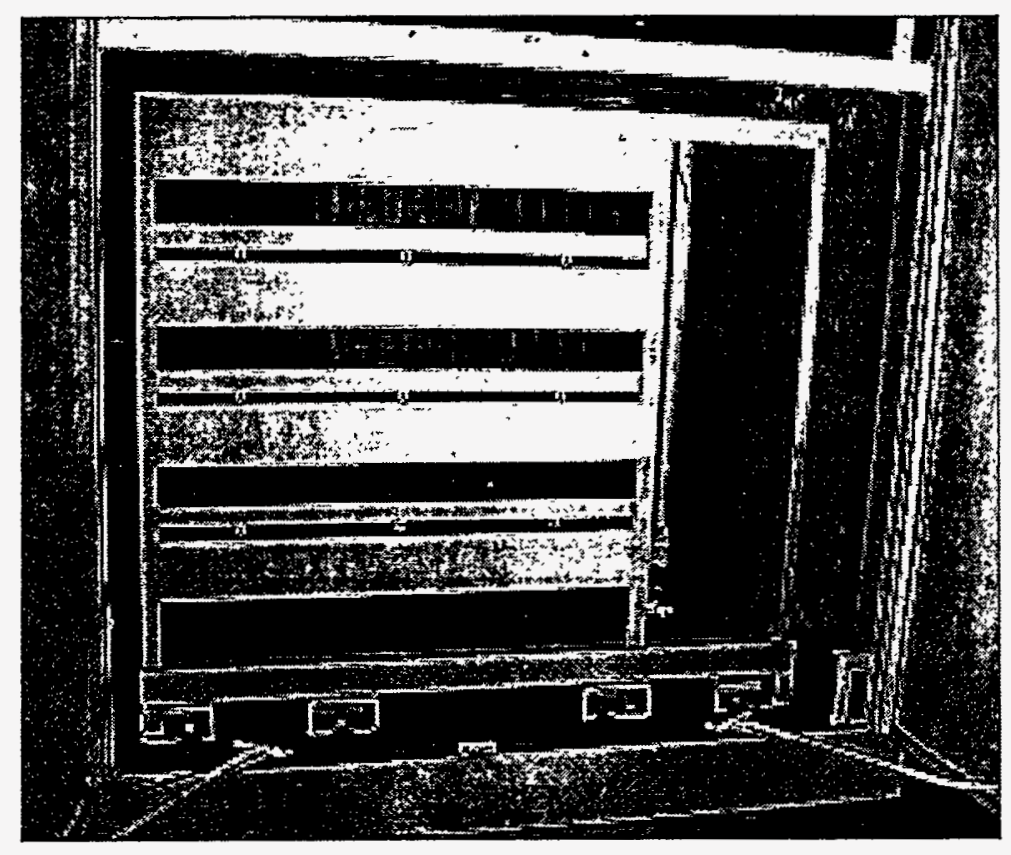

Figure 14. PQ2000 System Battery Module

\subsubsection{Chassis}

The chassis has been constructed such that the module can be disassembled easily to permit removal of the batteries for replacement. The inverter bridge is mounted on a separate assembly subpanel on one end of the module as shown

\subsubsection{Battery Trays}

Each module tray accommodates 12 batteries. See Figure 15. The batteries are held in place by compression packing between the trays. As an extra precaution, the bottom of each tray has been designed with a pan to hold a liquid volume equivalent to the amount of battery acid in a single battery.

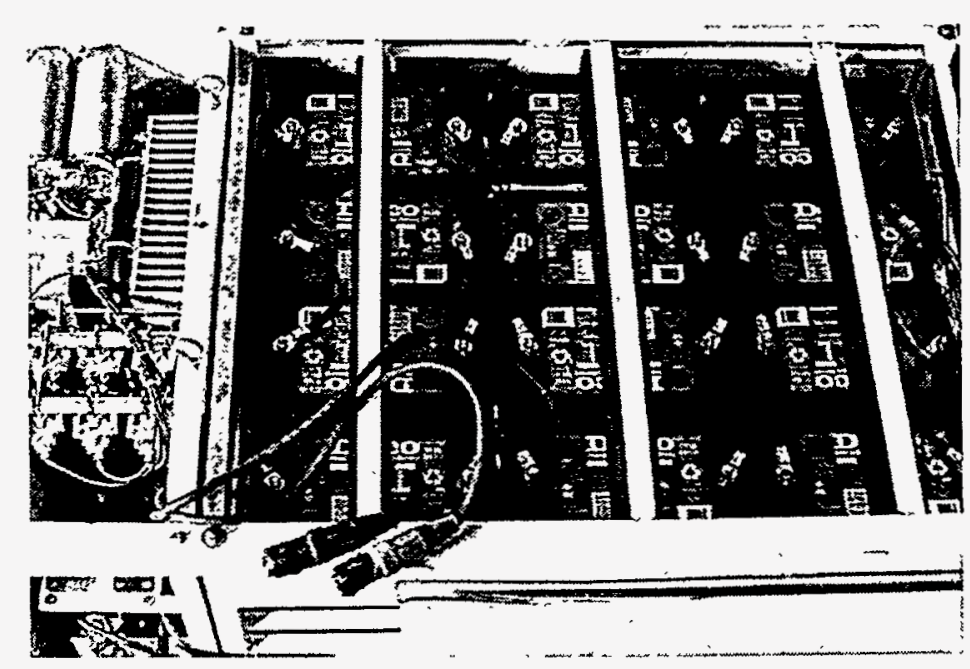

Figure 15. Top View of PQ2000 Battery Module 


\subsubsection{Inverter Bridge Mounting}

Pictured in Figure 16 is a battery module with the three-phase inverter bridge assembly mounted. The bridge assembly in the photograph is undergoing testing prior to final assembly.

\subsection{PCS Design}

The AC Battery PQ2000's PCS is comprised of eight (8) individual inverter bridges located on each of the eight (8) battery modules. The outputs of all eight (8) distributed inverter bridges are combined and collectively controlled to produce a single, unified voltage source. Each bridge consists of six (6) $1200 \mathrm{amp}, 1200$ volt, single Insulated Gate Bipolar Transistors (IGBTs) configured in a conventional three-phase bridge arrangement.

The AC Battery PQ2000 Power Quality System's Power

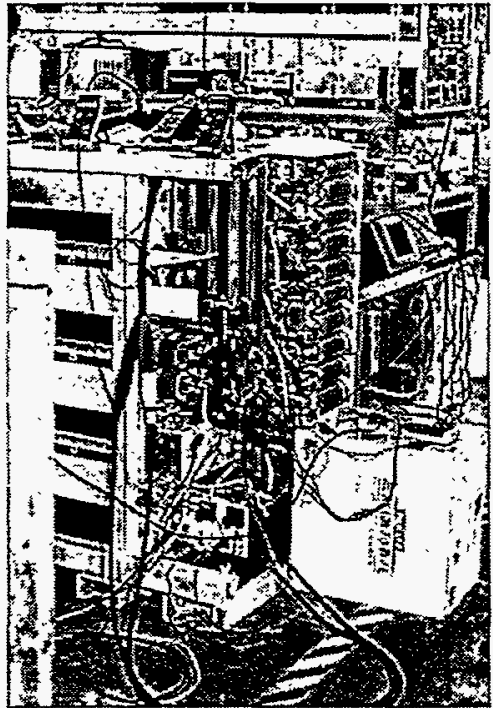

Figure 16. PQ2000 PCS Panel Under Test Conversion System (PCS) provides the interface between the AC Battery PQ2000's DC battery system and the $\mathrm{AC}$ system, and provides for charging and discharging of the batteries. The PCS, in conjunction with the AC Battery PQ2000 System Master Control, is capable of automatic unattended operation.

\subsubsection{Power Circuitry}

Input to and output from the AC Battery PQ2000 Power Quality System is $480 \mathrm{VAC}, 60 \mathrm{~Hz}$, three phase and is connected to the distribution feeder through a 480 V Static Automatic Transfer Switch (SATS).

\subsection{Static Automatic Transfer Switch (SATS) and Isolation Transformer}

The Static Automatic Transfer Switch (SATS) measures $12^{\prime} \mathrm{L}$ x $5.2^{\prime} \mathrm{W} \times 7.5^{\prime} \mathrm{H}$ and weighs approximately 7000 pounds. The isolation transformer measures $36 " \mathrm{~L} \times 48^{\prime \prime} \mathrm{W} \times 53$ " $\mathrm{H}$ and weighs approximately 2400 pounds.

\section{OPERATION}

The AC Battery PQ2000 Power Quality System is designed to operate as a voltage source supplying and maintaining all power levels up to a maximum rating of $2 \mathrm{MVA}$ for 10 seconds. The output of all eight (8) AC Battery Modules housed inside the system container are combined 
into a unified voltage source. The AC Battery PQ2000 Power Quality System will eliminate the potential effects of switching transients, voltage sags, and outages that may interrupt the Customer's manufacturing line, data processing, or other critical operations.

When a line disturbance is detected on the utility, the AC Battery PQ2000 Power Quality System will transfer power sensitive, electronic loads to the battery system and isolating them from the utility supply. While the AC Battery PQ2000 Power Quality System is operating and supplying power to critical bus loads (which conceivably could include an entire facility), the PQ2000 will operate at the utility frequency last monitored before the disturbance. The AC Battery PQ2000 Power Quality System will continuously monitor the utility to detect when the disturbance has cleared. When the utility is within normal tolerance and synchronized for 2 seconds, the AC Battery PQ2000 Power Quality System will reconnect the critical load to the utility. If for some reason the utility returns and is not in phase with the AC Battery PQ2000 Power Quality System, the AC Battery PQ2000 Power Quality System will first synchronize its output with the utility before allowing a transfer back to the utility supply.

If the utility does not return to nominal within the specified 2 MVA/10 second operating discharge time for the AC Battery PQ2000 Power Quality System, the AC Battery PQ2000 Power Quality System will transfer the load back to the utility. If the AC Battery PQ2000 Power Quality System has expended its available charge or has reached the thermal limits of operation, the AC Battery PQ2000 Power Quality System will, through self-monitoring, shutdown to protect its internal components.

The AC Battery PQ2000 Power Quality System is designed for complete automatic and unattended operation. External monitoring of the AC Battery PQ2000 can be accomplished through the use of a modem as outlined in other sections of this report. Local monitoring is annunciated on the LCD located inside the system container.

Charging of the AC Battery PQ2000 Power Quality System can be completed within 8 hours or less-depending upon the depth of discharge and total energy expended. Each battery module is designed with a separate $4 \mathrm{~kW}, 5 \mathrm{~A} @ 800$ VDC battery charger to provide for charging and equalizing the batteries. The batteries contained in the battery modules automatically recharge after each discharge. No floating charge is required or provided for the batteries. A biweekly equalizing charge for the batteries is programmed to take place during off-peak hours. The eight (8) battery modules housed in the system container will be independently charged and controlled at the same time for the duration of their charge cycle. The charging algorithm provided has been specifically designed for maximizing the efficiency of the charge cycle to restore the stateof-charge of the AC Battery Modules after discharge.

\subsection{Safety}

Safety systems included in the design of the AC Battery PQ2000 include a hydrogen gas detection and ventilation system, an integral smoke detector, and an acid spill containment area as standard features. See Figure 17. 
The hydrogen gas ventilation system is a forced air system that evacuates any hydrogen gas generated during charging through a network of tubing which runs from each battery in every battery module to one of four, two (2) inch PVC pipes running vertically in the system container. These pipes are vented to the outside and are connected to a common plenum equipped with a blower that pulls air through the pipes. The hydrogen sensor is mounted near the ceiling inside the

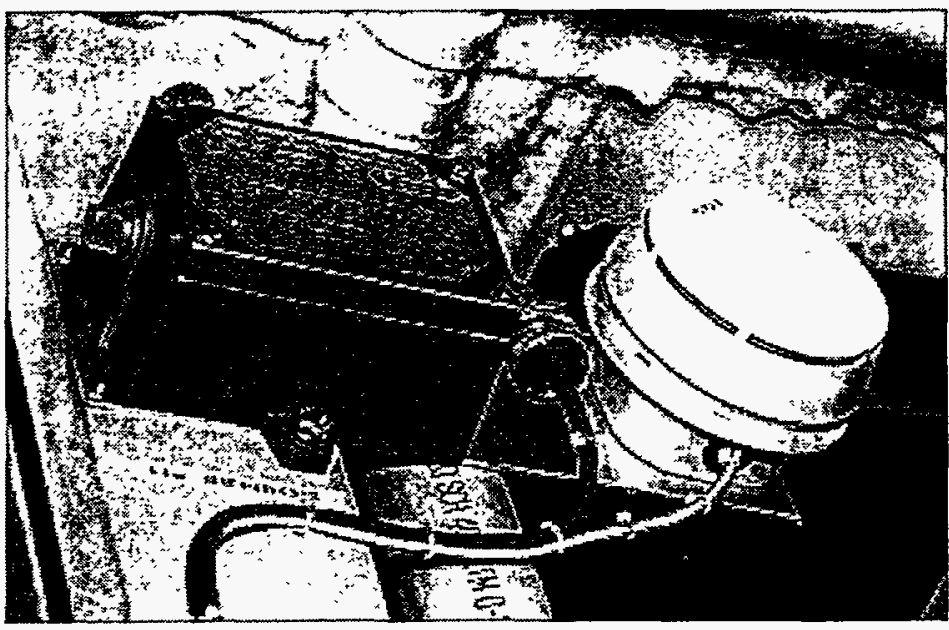

Figure 17. PQ2000 System Smoke and Hydrogen Detectors system container

If smoke or hydrogen gas is sensed, the AC Battery PQ2000 has been programmed to shutdown and annunicate an ALARM on both the local and remote SCADA System displays. The smoke detector is mounted near the ceiling inside the system container and is used to detect the presence of smoke which may have been generated from any type of combustion inside of the container.

As previously described, each of the eight (8) battery modules is comprised of four (4) vertically stacked trays of batteries. Each tray has a molded plastic liner which holds the individual batteries in place and provides the first level of acid spill containment. The molded tray design provides an effective containment system for acid spills equivalent to the volume of one battery on a per tray basis. For containment of larger acid spills, the second level of

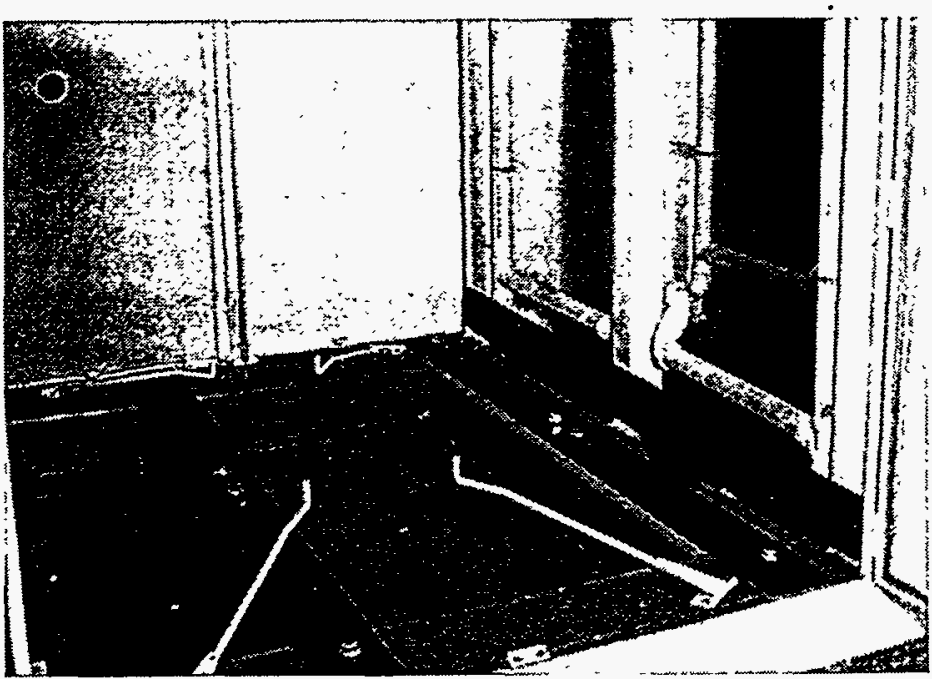

Figure 18. Container Acid Spill Containment Area acid spill containment is provided at the bottom of the system container. See Figure 18. The system container floor area is constructed of sheet steel that is covered with a minimum 15 mils of sprayed on ethylene methacrylic acid copolymer making it resistant to sulfuric acid. 
Additional safety features include protection from unauthorized entry into the container (door interlock), four fire extinguisher access ports on the container doors, frequency synchronization errors, low utility line frequency, voltage out-of-range, battery Over temperature, and container abnormal operating temperature.

\section{SUMMARY}

\subsection{Progress to Date}

As of the end of August, 1995, fabrication of the AC Battery PQ2000 Power Quality System was largely complete with subassembly testing underway. Fabrication of the container was completed and the bridges were under test. Delays to the project schedule of approximately one month were estimated due to unanticipated delays in delivery and extended testing of the static switch.

\subsection{Work to be Completed}

Final component testing of the bridge assemblies needs to be completed as does full system integration and final testing. No problems are anticipated at this point. It is expected that final fabrication, integration, and system testing will begin immediately after component testing has been completed in October, 1995. It is estimated that Factory Acceptance Testing will commence and conclude around end of December, 1995.

Documentation support for the $\mathrm{PQ} 2000$ System is an ongoing project. Testing protocols for final subassembly testing have been developed, but full system Operation \& Maintenance Manuals will yet need to be written. However, preliminary manuals will be ready in time to send to the field along with the first PQ2000. 
APPENDIX A 


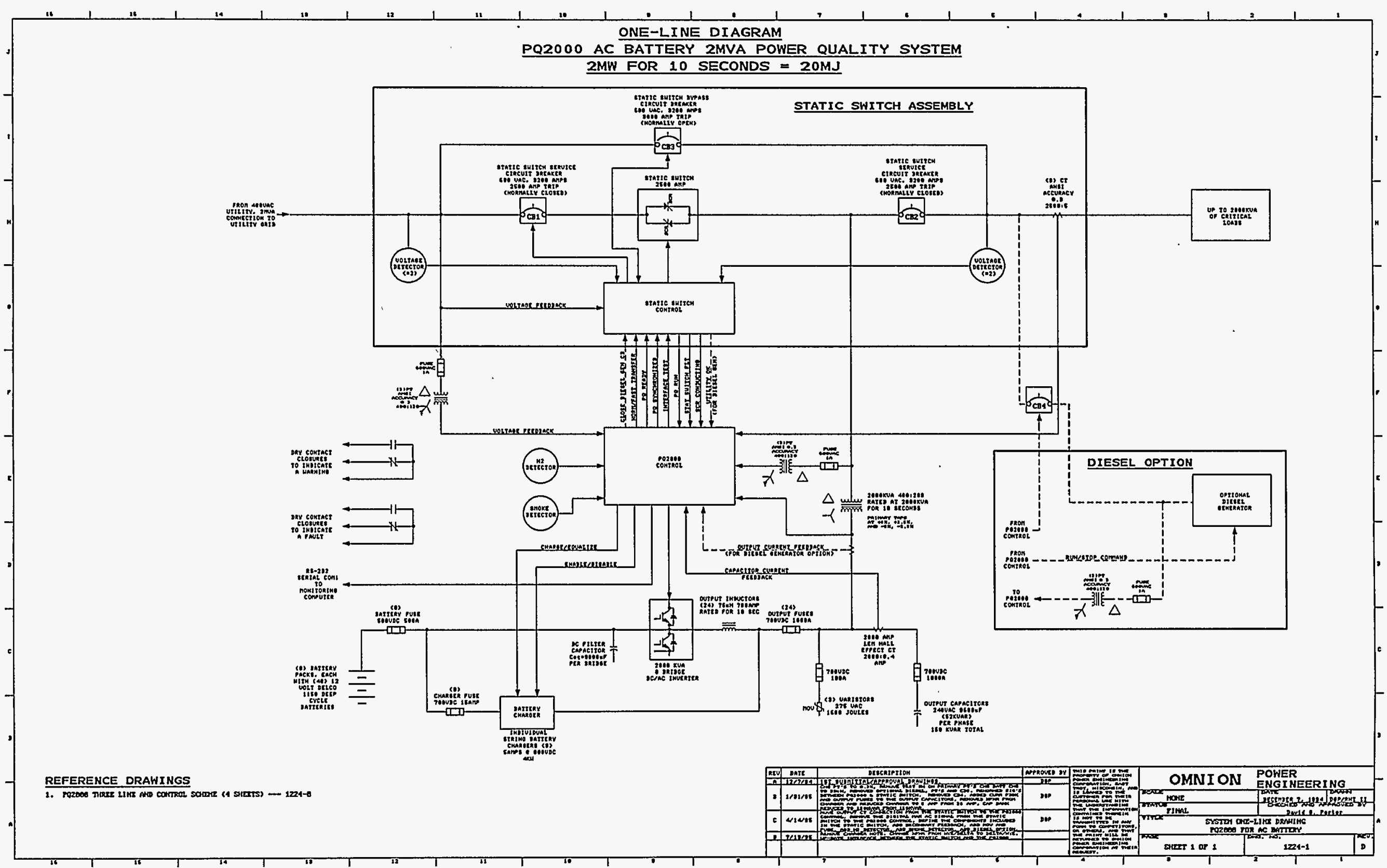




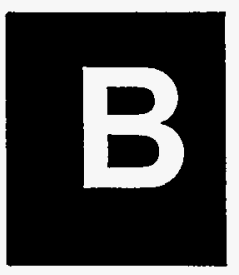

APPENDIX B 


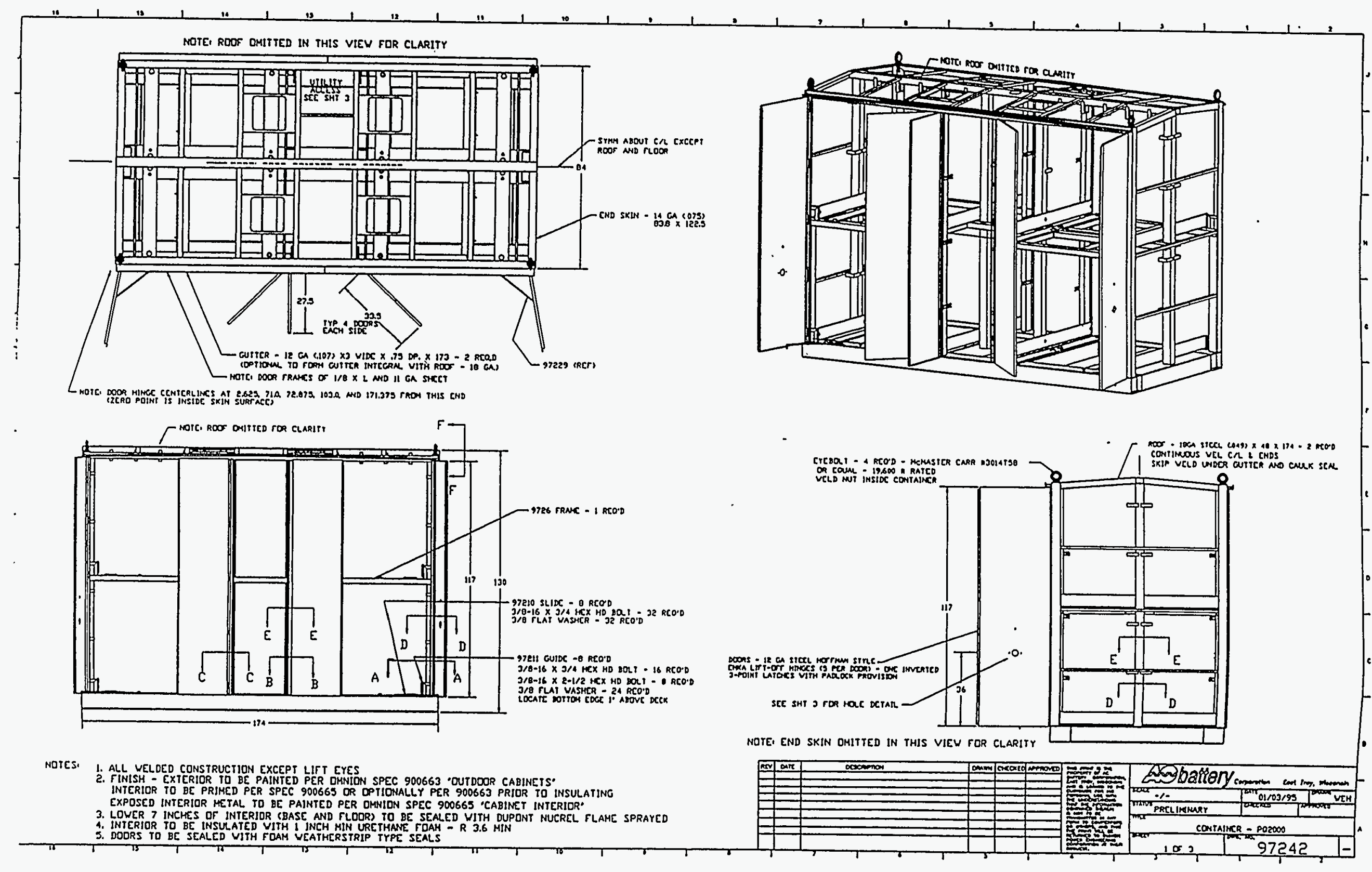

